\title{
THE TREATMENT OF SUBACUTE BACTERIAL ENDOCARDITIS WITH PENICILLIN ${ }^{1}$
}

\author{
By ARTHUR L. BLOOMFIELD, CHARLES D. ARMSTRONG, AND \\ WILLIAM M. M. KIRBY \\ (From the Department of Medicine, Stanford University School of Medicine, \\ San Francisco 15)
}

(Received for publication November 3, 1944)

The first reports on treatment of subacute bacterial endocarditis ( $S$. viridans) with penicillin were not encouraging (1). It was recognized, however, by the Committee on Chemotherapeutics and Other Agents that the subject required further study, and it was planned to treat more patients when larger amounts of penicillin, which seemed to be necessary, should be available. Meanwhile, improvement was reported (2) in some cases, and possible cure in others, when penicillin and heparin were given at the same time. It seemed desirable, however, to try out the effects of penicillin alone, given in sufficient dosage to put the matter to a critical test. The present report concerns the results in 11 cases which were managed according to the following plan.

\section{SPECIFICATIONS FOR SELECTION OF CASES}

The criteria for the selection of patients for treatment were as follows:

1. Positive blood cultures were obtained in our own laboratory.

2. The strains of non-hemolytic streptococci were all sensitive in the test-tube with a concentration of 0.1 units of penicillin per milliliter of culture medium. In all but one case, the strains actually were inhibited by smaller amounts of penicillin.

3. The patient's condition was not desperate. The known duration of the disease was not over a few months. There were no frank signs of cardiac failure. Three cases in a sense were exceptions: Case 10 in which there was incipient decompensation in association with a marked valve lesion, Case 2 who ran a stormy febrile course with over 500 colonies of $S$. viridans per ml. of blood before treatment, and Case 3 who was very ill with high fever and considerable anemia.

1 The penicillin was provided by the Office of Scientific Research and Development from supplies assigned by the Committee on Medical Research for Clinical Investigations recommended by the Committee on Chemotherapeutic and Other Agents of the National Research Council.
4. Treatment was not undertaken unless the patient agreed to stay in the hospital for 6 to 8 weeks or more for continuous therapy.

\section{PLAN OF ATTACK}

Since previous experience had shown that even large doses of penicillin over brief periods did not effect regular cures, it was decided to give the material for at least 6 to 8 weeks. It was hoped that a continuous assault of this sort might eradicate bacteria lurking in the depths of vegetations and that the latter might become organized and tend to "heal." The general plan was to give 200,000 to 300,000 units in the 24 hours by continuous intravenous drip for 3 weeks and thereafter 120,000 to 200,000 units per day in 8 intramuscular injections (5000 units per ml. of saline) for 3 to 5 weeks. Most of the patients were treated for 8 weeks without interruption. The only therapy aside from penicillin was general supportive and nursing measures and in some cases transfusions. Many of the patients were confined to bed only until the temperature fell. They were then up quietly about the ward. Frequent physical examinations were made with special reference to embolic lesions, petechiae, the cardiac signs, etc., and numerous blood cultures were taken, for the most part with penicillinase, so that the results were not confused by penicillin carried over into cultures from the blood stream. No heparin was used.

The evidences of a renal lesion were very carefully followed by means of "Addis quantitative counts" of the formed elements in the sediment to try to determine whether treatment influenced the process.

The most important clinical features are summarized in Table $I$ and in the following brief case reports.

Case 1. A 22-year-old ditch-digger had always been mentally defective. $\mathrm{He}$ was also said to have had a heart murmur since childhood. He was perfectly well until 3 months before entry when he suddenly developed chills and fever with malaise and weight loss. Several blood cultures were positive for $S$. viridans and he was sent to Stanford Hospital for penicillin treatment. He was a big, heavy-set man. There was cardiac enlargement .with a loud systolic murmur widely heard, moderate systolic hypertension in the upper extremities, and absence of palpable pulsations in the femoral, popliteal, and foot arteries. It was concluded that he had coarctation of the aorta and possibly an interventricular septal defect, with superimposed $S$. viridans infection. Treatment and other data are given in Figure 1 and the tables. 
ARTHUR L. BLOOMFIELD, CHARLES D. ARMSTRONG, AND WILLIAM M. M. KIRBY

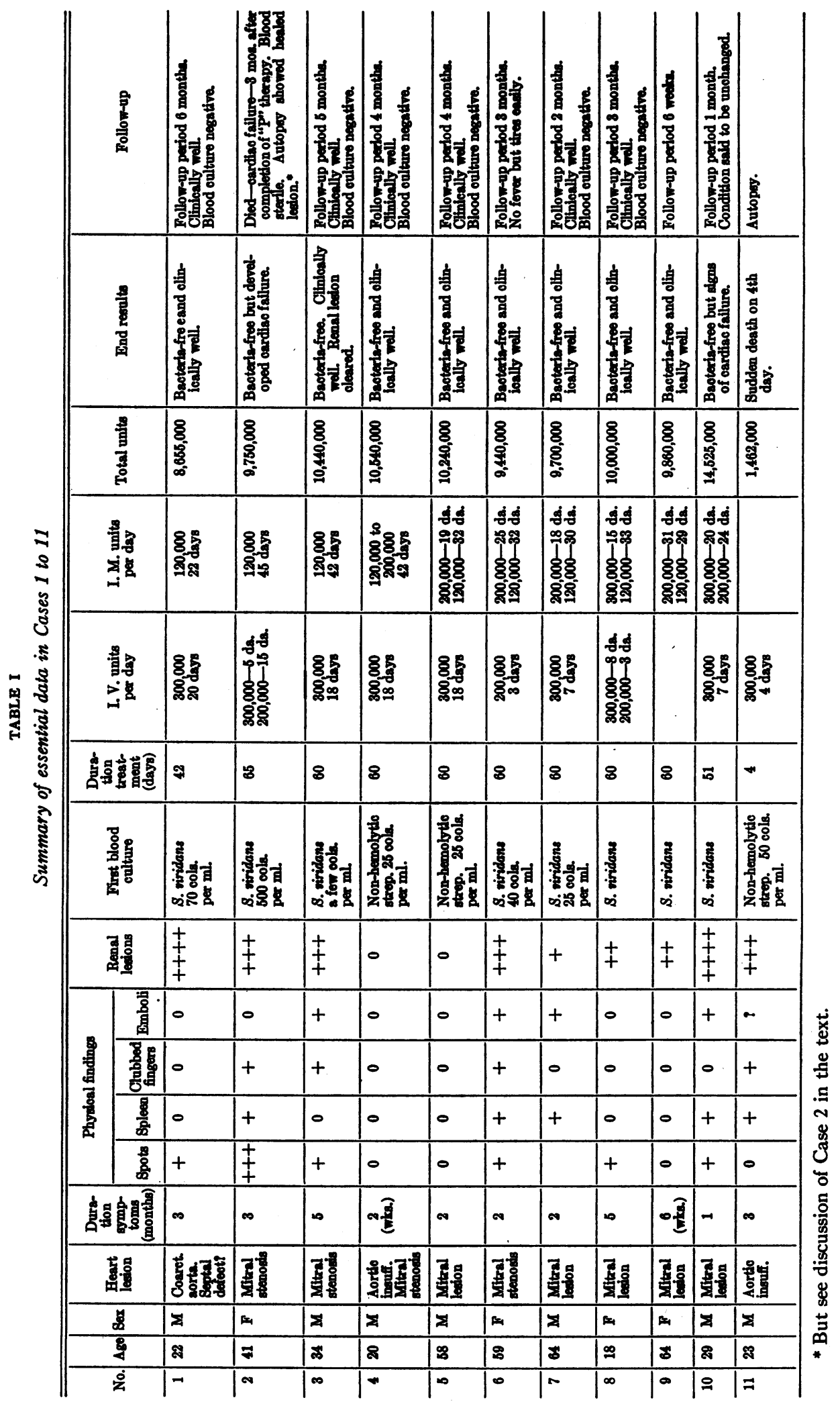




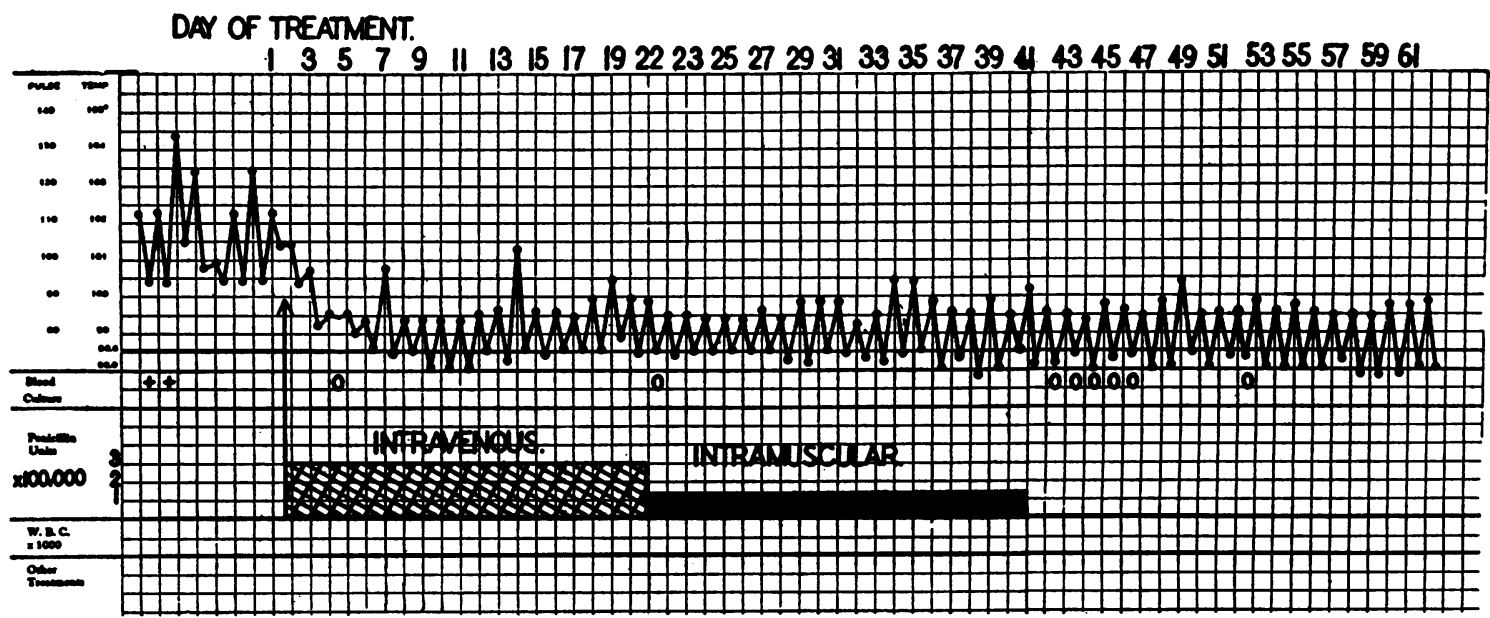

Fig. 1. Complete Temperature Chart of Case 1 in Relation to Therapy and Blood Cultures

The persistent slight elevations of temperature after the initial drop are unexplained. Thrombophlebitis, pyrogenic reactions, reactions associated with the cardiac lesion, or small emboli are possibilities. Six months later the temperature was normal.

Temperature fell promptly but he continued to have slight elevations throughout his hospital stay. The significance of these was not clear. He left after 62 days, bacteria-free and clinically well. Last follow-up visit, 6 months after penicillin was concluded, found him well and active and bacteria-free but with physical signs unchanged. At this time, the temperature was entirely normal and his lesion was regarded as "healed."

Case 2. A 41-year-old school teacher had always been well and gave no history of rheumatic fever, but a heart murmur had been diagnosed 10 years ago. Three months before entry, she developed fever and prostration and had been ill ever since. Several blood cultures were said to be positive for $S$. viridans. On examination, she seemed very ill, with high fever and rapid pulse. She was covered with innumerable large and small petechiae. There was early clubbing of fingers. The heart was enlarged and there were typical signs of mitral stenosis. Blood cultures yielded over 400 colonies of $S$. viridans per $\mathrm{ml}$. of blood. The impression of one examiner was "she is going down hill fast and a good therapeutic result would be miraculous." Penicillin was started (see Figure 2 and the tables) by continuous intravenous drip at the rate of 300,000 units per day. There was remarkably prompt improvement of general symptoms with fall in temperature although slight elevations continued. There was rapid clearing of the petechiae although some new ones appeared for 2 weeks. The blood stream was cleared in a few days and all subsequent cultures were negative After being rendered bacteria-free, she developed curious red tender symmetrical swellings of all fingers and toes, apparently associated with acute progression of "clubbing." Studies of blood vessels and of capillary circulation were not remarkable. Later she developed a frank arthritis of the fingers with smooth shiny skin. Signs of cardiac failure, not present on entry, now began to develop and she died on the 164th day of hospital stay in an acute paroxysm of dyspnea after being bacteria-free for over 5 months. The temperature at this time had been entirely normal or subnormal for several weeks.

Autopsy. Pertinent points in the autopsy report are as follows (Dr. J. B. McNaught): "The mitral valve as viewed from above prior to opening is moderately irregular, nodular, and apparently not efficient, but not decidedly stenosed. Upon opening it, the circumference is $9 \mathrm{~cm}$., but both flaps in the midportion have thick nodular, rather rigid shrunken edges. The anterior cusp is considerably shortened in the distance from base to free edge and has a $0.4 \mathrm{~cm}$. round hole with raised edges $0.5 \mathrm{~cm}$. from the free edge. There are no soft vegetations or thrombi and calcium can be palpated in some of the nodules. Two chordae tendinae are thickened up to $0.5 \mathrm{~cm}$. and shortened and the endocardium beneath the anterior flap is thick and white. There is a $1.5 \times 1$ $\mathrm{cm}$. granular patch on the endocardium of the left ventricle $1.5 \mathrm{~cm}$. below the aortic valve. The ventricular surface of the posterior flap is roughened with calcification."

Microscopic examination of the heart showed: "The mitral valve leaflets are greatly thickened centrally by hyalinized fibrous tissue with very few nuclei, and there are small areas of calcification deep within the fibrous tissue. There are also surface areas of more cellular well vascularized fibrous tissue with a few lymphocytes, and polymorphonuclear leukocytes and scattered large mononuclear cells some of which contain hemosiderin. These areas have the appearance of organization of thrombotic tissue and occasionally enclose small areas of necrotic thrombus some of which contain many Gram + cocci singly, by pairs and in short chains. The outermost surface is roughened by areas of pink staining 


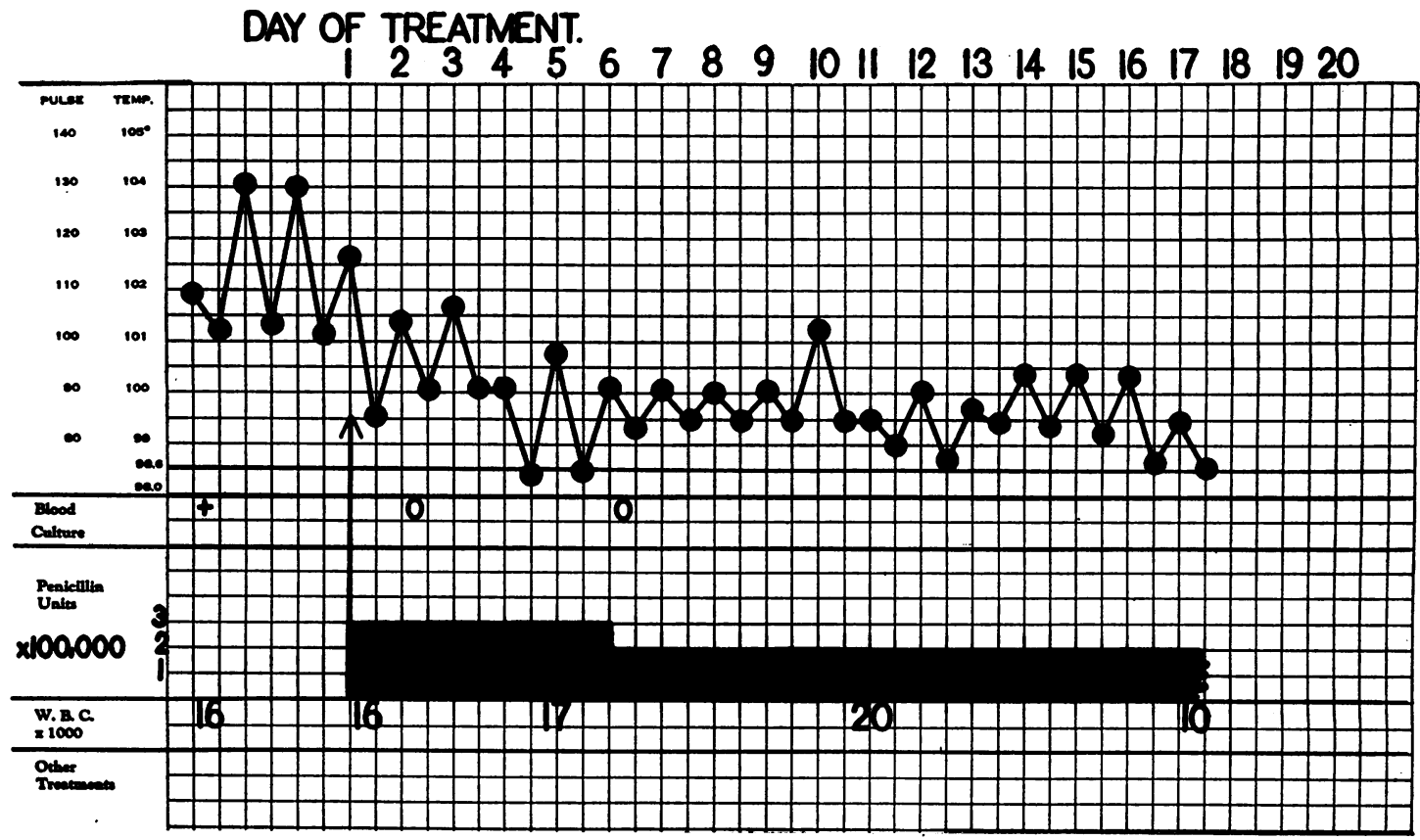

Fig. 2. Shows Temperature Curve for First Three Weeks of Treatment

She continued to have a variable low fever throughout her long hospital stay (even after 3 blood cultures were sterile) until the last few weeks when the temperature became subnormal. As in Case 1, the exact cause of these elevations was not always clear.

practically acellular thrombotic material in which fibroblasts are growing from beneath. They sometimes contain a few polymorphonuclear leukocytes. Many of these nodules are quite cellular and vascular as though recently organized, and an occasional such nodule contains within its depths small islands of necrotic thrombus rich in pleomorphic Gram positive cocci singly and in short chains. None of these bacteria-laden areas are found exposed on the surface of the valve.

"The chordae tendinae are thickened, similar to the valve. The endocardium of the auricle and ventricle are roughened by organizing vegetations in which no bacteria are found. The myocardium at the base of the mitral valve and the apex of the papillary muscles is irregularly scarred. Elsewhere, there is a slight increase in fibrous tissue about many of the blood vessels but no thickening of their intima and there are no cellular collections suggesting Ashoff bodies. The myocardial fibers are normal with no abnormal cellular infiltrations. Large branches of the coronary arteries show mild subintimal fibrosis.

"As regards the kidneys, in general the histology in both is normal except for congestion. However, meticulous search reveals rare glomeruli which are partially adherent to their capsule, slight capsular proliferation, and slight tuft fibrosis which may well represent a late stage of focal glomerulonephritis with no fresh hyalin lesions. No blood is found in capsular spaces, but rare tubules contain red blood cells. There is granular mate- rial in some of the tubules and rare hemoglobin stained casts. The right kidney contains a sunken area of old infarction with diffuse fibrosis, fibrosed glomeruli, areas of necrosis containing hemosiderin and shadows of necrotic tubules. There are moderate numbers of lymphocytes in this area which invade the adjacent more normal renal tissue and here a few tubules contain polymorphonuclear leukocytes. A small artery at the apex of the infarct is obliterated by fibrous tissue. The left kidney contains a similar but narrower and more fibrosed area."

These findings raise a number of problems of interest and importance. At the time of autopsy, the lesions appeared to be healed; no coarse vegetations were any longer present, only small partly calcified flat plaques remained. Culture from the heart's blood yielded no growth and no bacteria were seen in smears from the surface of the lesions. Many blood cultures had been negative over a period of several months and the temperature was normal for a month before death. None the less unmistakable gram-positive cocci were seen in the depths of the "healed" valve lesions. A good deal of pleomorphism and variability in staining reaction were observed. Were these bacteria dead and sealed off in pockets of old organized vegetation? Were they viable, but sealed off, or were there actually streptococci in the blood stream which were not recovered by the relatively crude method of blood culture? Had she not died of cardiac failure, would there later have been a clinical relapse of bacterial endocarditis? None of these 
questions can be answered definitely and one can only record the facts and wait for longer follow-up periods in other cases. The findings do however support the position that penicillin treatment should be given over a long period of time, perhaps over many months, continuously or intermittently.

Case 3. A 34-year-old accountant had had polyarthritis at the age of 15 . A heart murmur was known to be present since that time. Five months before entry, he developed an indefinite febrile illness. There was no benefit from 4 months' treatment with sulfonamides. On examination, he appeared febrile and ill and there was marked weight loss. There were typical signs of mitral stenosis, a palpable spleen, early clubbing of fingers, and a few petechiae. He was moderately anemic and there was evidence in the urinary sediment of a mild glomerulitis. The blood culture yielded non-hemolytic streptococci. He was given 300,000 units of penicillin daily by intravenous drip for 18 days and then 15,000 units intramuscularly every 3 hours for 32 days-a total of $10,440,000$ units in 2 months. The high temperature on entry fell in a few days and remained essentially normal with the exception of 2 pyrogenic reactions (see Figure 3 and the tables). He gained $20 \mathrm{lbs}$., recovered his appetite and good spirits, and changed from what appeared to be a dying man to one who seemed perfectly well. The heart murmur persisted unchanged and the pulse remained slightly rapid. The signs of the renal lesion disappeared. Blood cultures promptly became sterile and remained so on many occasions.
Follow-up studies after a period of 5 months showed him to be clinically well with entirely normal temperature and negative blood cultures. $\mathrm{He}$ had been actively at work with no bad results.

Case 4. A 20-year-old truck driver had always been well except for rheumatic fever at the age of 5 followed by signs of aortic insufficiency. Two weeks before entry he felt tired and developed high irregular fever. On examination, he was a big healthy looking young man with typical signs of aortic insufficiency. The blood pressure was 160/?. The spleen was not palpable; there were no petechiae or embolic phenomena. Blood culture yielded 25 colonies per $\mathrm{ml}$. of non-hemolytic streptococcus. He received a total of $10,540,000$ units of penicillin over a period of 60 days (see Figure 4 and tables). In this case, although the blood stream was promptly and permanently sterilized the temperature fell quite gradually. It was, however, perfectly normal for some days before discharge. He gained weight, all symptoms disappeared, and he seemed entirely well. He was carefully examined after a follow-up period of 4 months and still appeared "cured" with normal temperature and negative blood cultures. The signs of aortic insufficiency were unchanged.

The persistence of fever in this case, whatever the cause may have been, is an argument in favor of prolonged penicillin therapy.

Case 5. A 58-year-old painter had a bout of hemoptysis and dyspnea 4 years ago and was then told he had a leaky heart valve although there was no history of

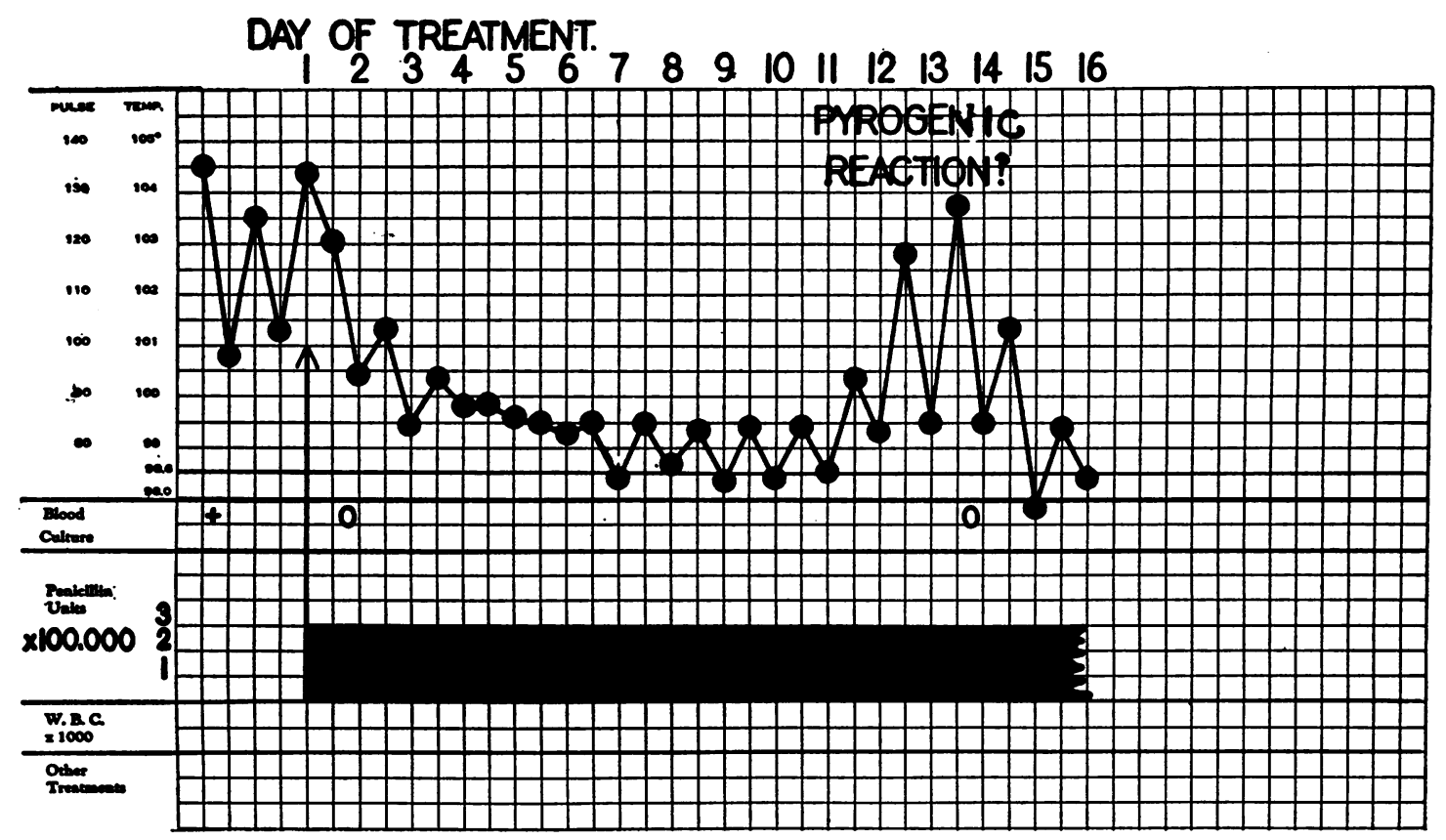

Fig. 3. Temperature Curve for First 16 Days of Treatment

Remarkably prompt fall. With the exception of another febrile reaction from the 17 th to the 19 th days, probably pyrogenic, the curve remained essentially normal until discharge on the $83 \mathrm{~d}$ hospital day. 


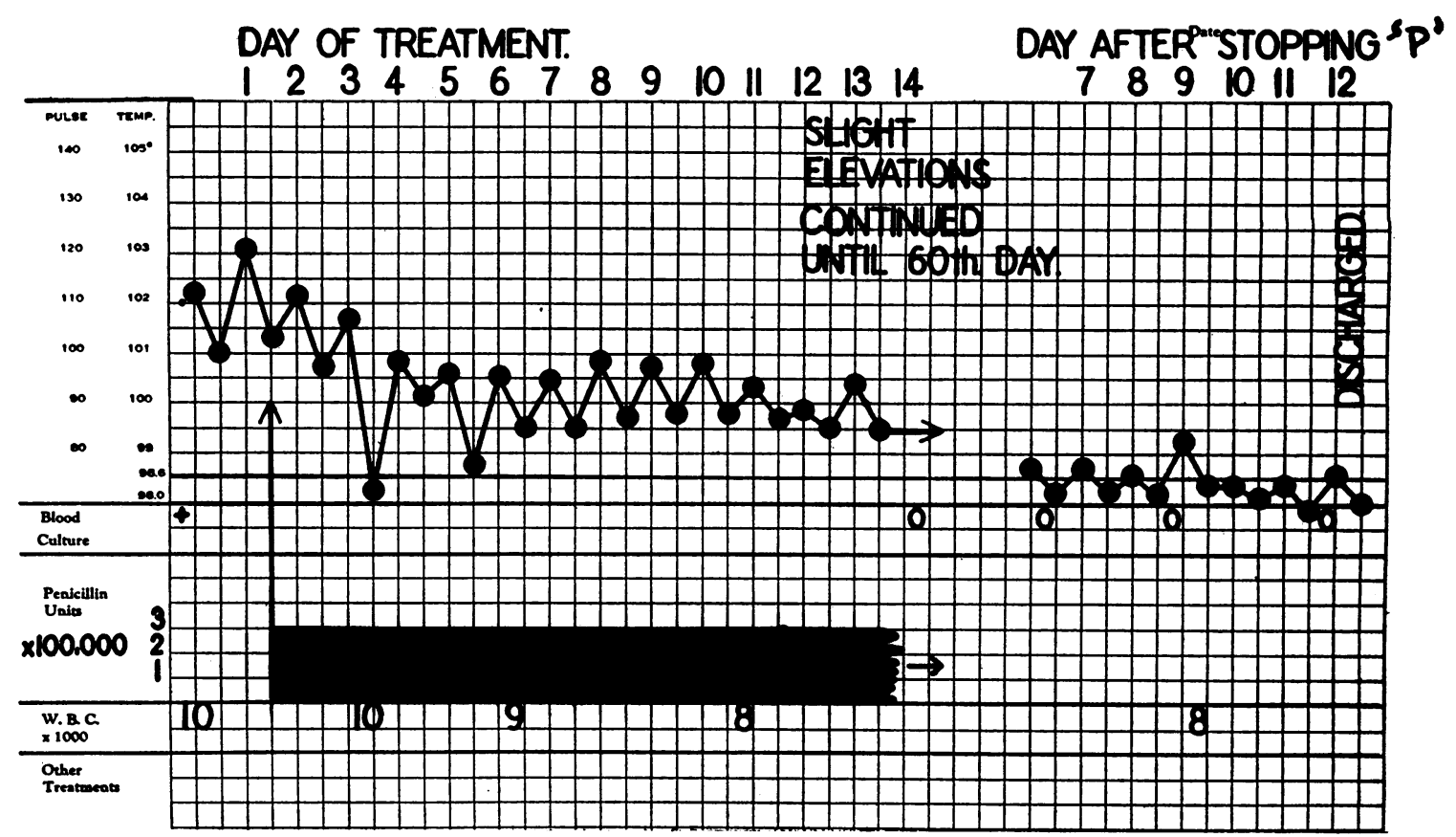

Fig. 4. Temperature Curve of Case 4

The persistent elevation of temperature was not explained by obvious emboli or by phlebitis associated with intravenous drip.

rheumatic fever. He was perfectly well until about 8 weeks before entry when he developed chills, fever, aching, and malaise. Blood culture was found positive for non-hemolytic streptococcus and intensive sulfonamide therapy was given for several weeks without improvement. On entry, he had a moderate fever and a short loud systolic murmur, loudest at the mitral area. No diastolic murmur could be made out. The blood culture was again positive for non-hemolytic streptococcus (25 cols. per ml.). He received $10,240,000$ units of penicillin over a 60 -day period (see Figure 5 and the tables). The temperature dropped promptly but on the 5 th day of treatment, he had a chill with high fever and a crop of petechiae. The blood culture, previously negative, again showed a few colonies of non-hemolytic streptococcus. Apparently, a bit of infected vegetation had broken off. Thereafter, there was gradual but steady improvement, although there were several more sharp rises of temperature, perhaps due to emboli, but without positive blood cultures. During the last 3 weeks of treatment and during subsequent hospital stay, the temperature was normal and he left the hospital feeling perfectly well.

At the end of a 4 months' follow-up period, he seemed in exuberant good health. He was working and had no symptoms. Blood culture was sterile. The systolic murmur was unchanged.

Case 6. A 59-year-old woman was known to have had a valve lesion for several years at least. Two months before entry she noticed weakness and fever.
There had been splinter hemorrhages in the nail-beds, and blood culture was reported positive for $S$. viridans. On examination, she was an elderly, febrile, prostrated woman. The heart was enlarged with typical snapping first sound of mitral stenosis followed by a loud systolic murmur. There was clubbing of fingers. Blood culture yielded 40 colonies per $\mathrm{ml}$. of $S$. viridans. Penicillin was given at the rate of 200,000 units per day by continuous intravenous drip for 3 days, then by intramuscular injection every 3 hours at the rate of 200,000 units per day for 25 days, and then at the rate of 120,000 units per day for 32 days, a total of $9,440,000$ units in 60 days. On the day after treatment was started, less than one colony per $\mathrm{ml}$. was obtained in blood culture and from that time on, all cultures (13 in number) were sterile. Temperature after the third day (see Figure 6 and the tables) was low and after penicillin was stopped, it was not above $37.6^{\circ} \mathrm{C}$. (rectal). There was steady clinical improvement and she left the hospital feeling very well. Three months later, follow-up studies in the hospital found her still somewhat weak, rectal temperatures were $37^{\circ} \mathrm{C}$. and physical examination was not remarkable except that signs in the heart were unchanged.

It seems probable that her infection has been eliminated but she seems weaker than before the illness, which is not remarkable at her age.

Case 7: A 64-year-old man had no story of rheumatic fever or old heart lesion. Two months before entry, several teeth were extracted. The operation was followed by malaise, weakness, fever, and $30 \mathrm{lbs}$. weight 
DAY OF TREATMENT.

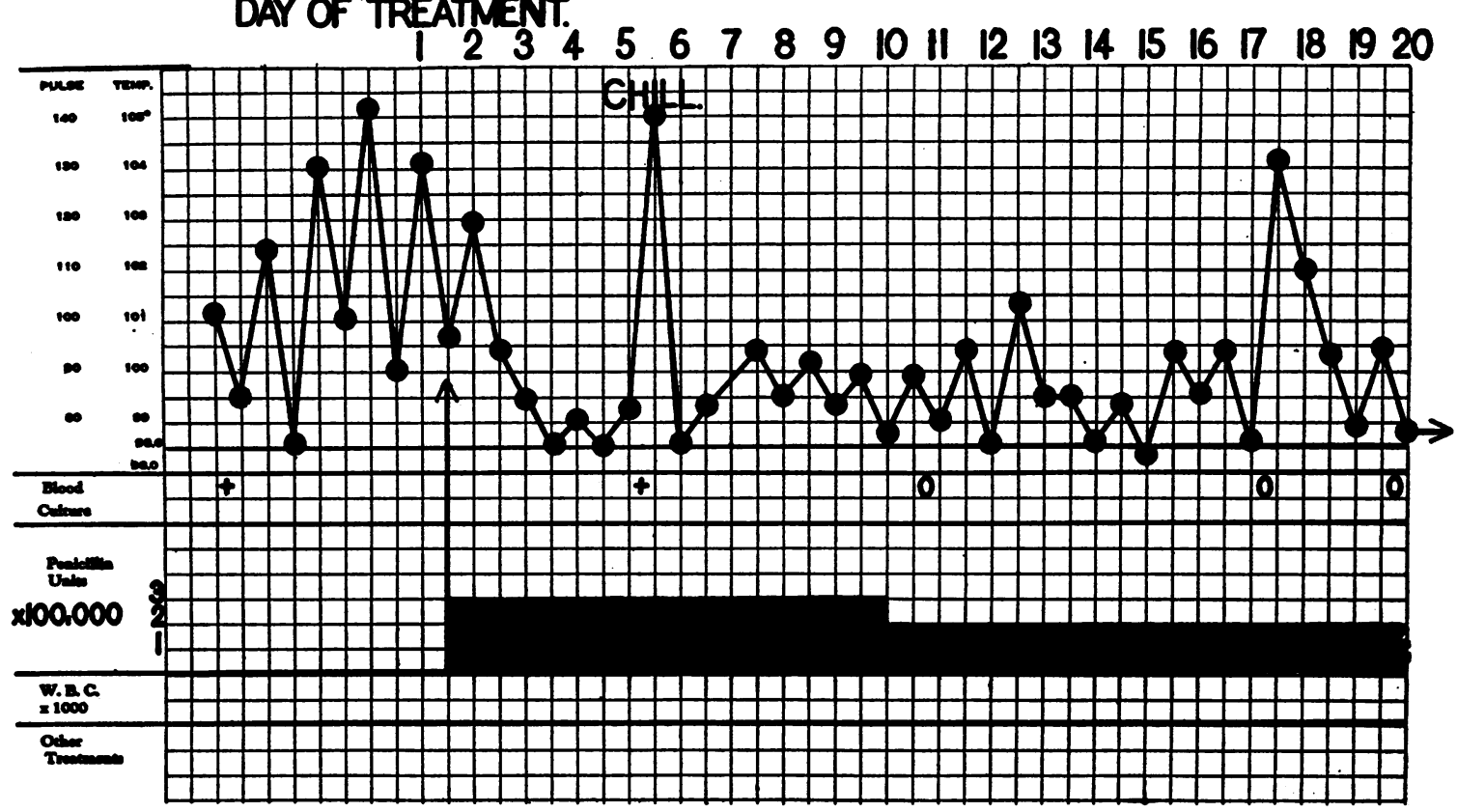

Fig. 5. Temperature Curve from Case 5 Showing first 3 Weeks of Treatment

Occasional spikes of fever occurred during the first months. Thereafter the temperature was normal.

loss. On examination, he was a little pale and looked tired and worn. The first sound at the apex was followed by a loud rough murmur, typical of organic valvular disease. The spleen was readily felt. There was a tender area over the tendons of the right wrist. Two blood cultures each yielded about 25 colonies of $S$. viridans per $\mathrm{ml}$. He was treated for 60 days with penicillin, receiving a total of $9,700,000$ units. Blood culture

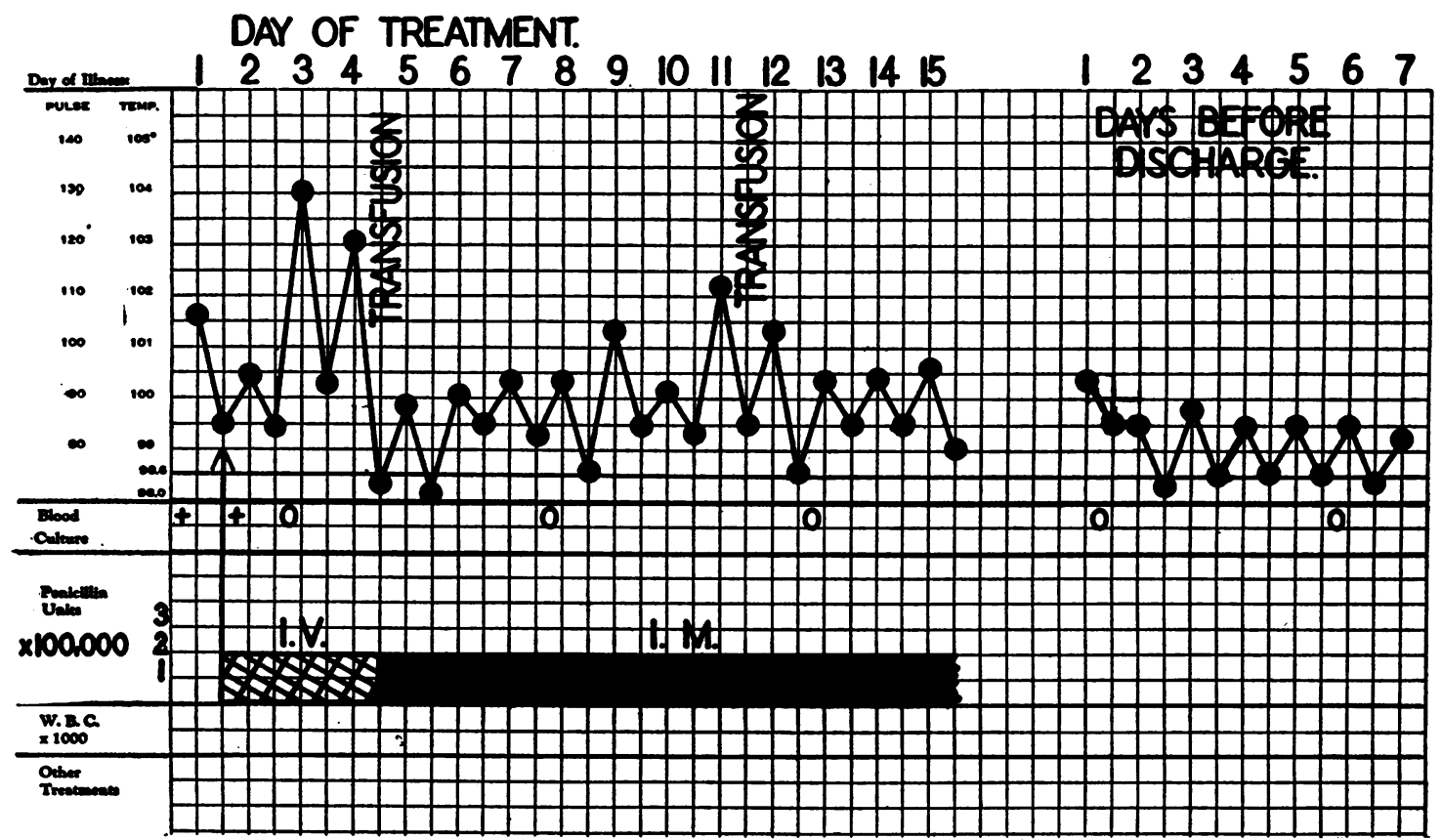

Fig. 6. Temperature Chart of Case 6 for First 2 Weeks of Treatment and of Last Week in Hospital After Penichllin Was Stopped 
(with penicillinase), made 2 hours after the intravenous drip of penicillin was started, yielded no growth and all subsequent cultures were sterile. There was a prompt drop of temperature (see Figure 7 and the tables) and within a few days he felt much better and ran an essentially uneventful course. On discharge on the 64th day, and 4 days after stopping penicillin, the temperature was normal and he felt perfectly well. The spleen was no longer palpable, but the heart sounds were unchanged. Follow-up visit 2 months later found him well and at work, and blood culture was sterile.

Case 8. An 18-year-old housewife had had rheumatic fever at the age of 10 . She was in bed for a long time, was left with a heart murmur, but was essentially well. About 4 months before entry, she developed fever, malaise, joint pains, and palpitation, and 7 blood cultures were reported positive for $S$. viridans. Sulfadiazine was given without benefit in another hospital. On examination, she did not appear very ill. There was moderate fever. There was a thudding first sound at the apex followed by a loud musical systolic murmur. A soft echoing diastolic murmur was also heard to left of sternum. It was thought that she probably had an old rheumatic mitral lesion with subacute bacterial endo- carditis, and blood culture again yielded $S$. viridans. There were a few petechial spots but the spleen was not felt. There was no evidence of a renal lesion. She received 300,000 units of penicillin daily by intravenous drip for 8 days and slightly smaller amounts for the next 3 days. Thereafter intramuscular injections were given in amounts of 120,000 to 200,000 units daily up to 60 days $-a$ total of $10,000,00$ units. There was a prompt drop of temperature to normal (see Figure 8 and the tables). The blood cultures became negative and she felt well. Her course was uneventful except for 2 spikes of fever, probably due to pyrogenic solutions, and she left the hospital well, but with the heart signs unchanged. Follow-up studies 6 weeks later showed her to be the picture of health, with no symptoms, normal temperature, and negative blood culture.

Case 9. A 64-year-old woman had had "rheumatic fever" 18 years ago. Six weeks before entry, she developed chills and fever, and blood cultures were found positive for $S$. viridans. She was treated for 4 weeks with sulfathiazole without benefit. Examination showed a thin, tired, febrile elderly woman. The heart was enlarged, the rate $140-150$. There were typical signs of mitral stenosis. The spleen was not felt; there were no

\section{DAY OF TREATMENT.}

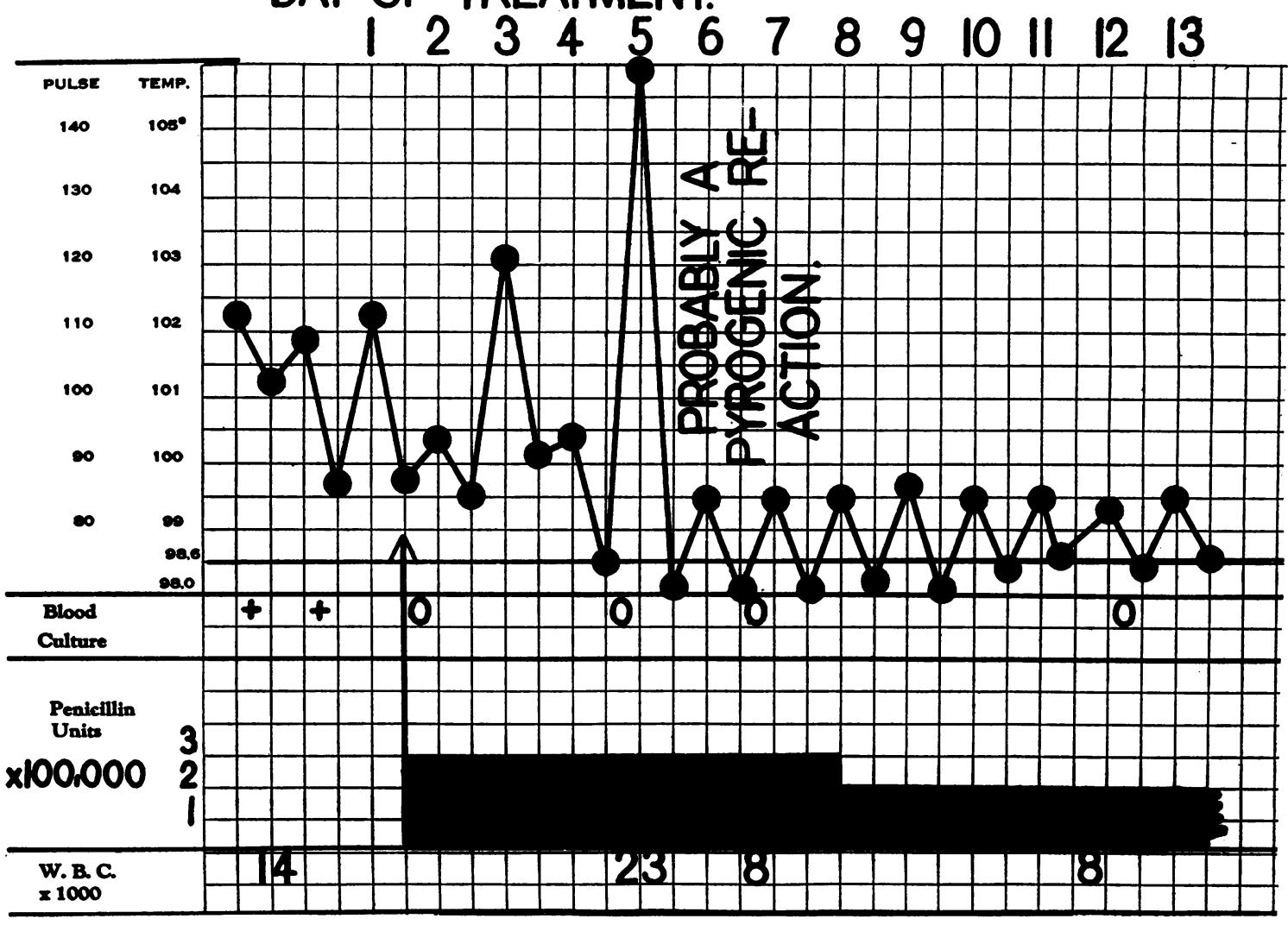

Fig. 7. Temperature Curve of Case 7 for First 2 Weeks of Treatment

From this time on, aside from occasional elevations, the temperature was essentially normal. 


\section{DAY OF TREATMENT.}

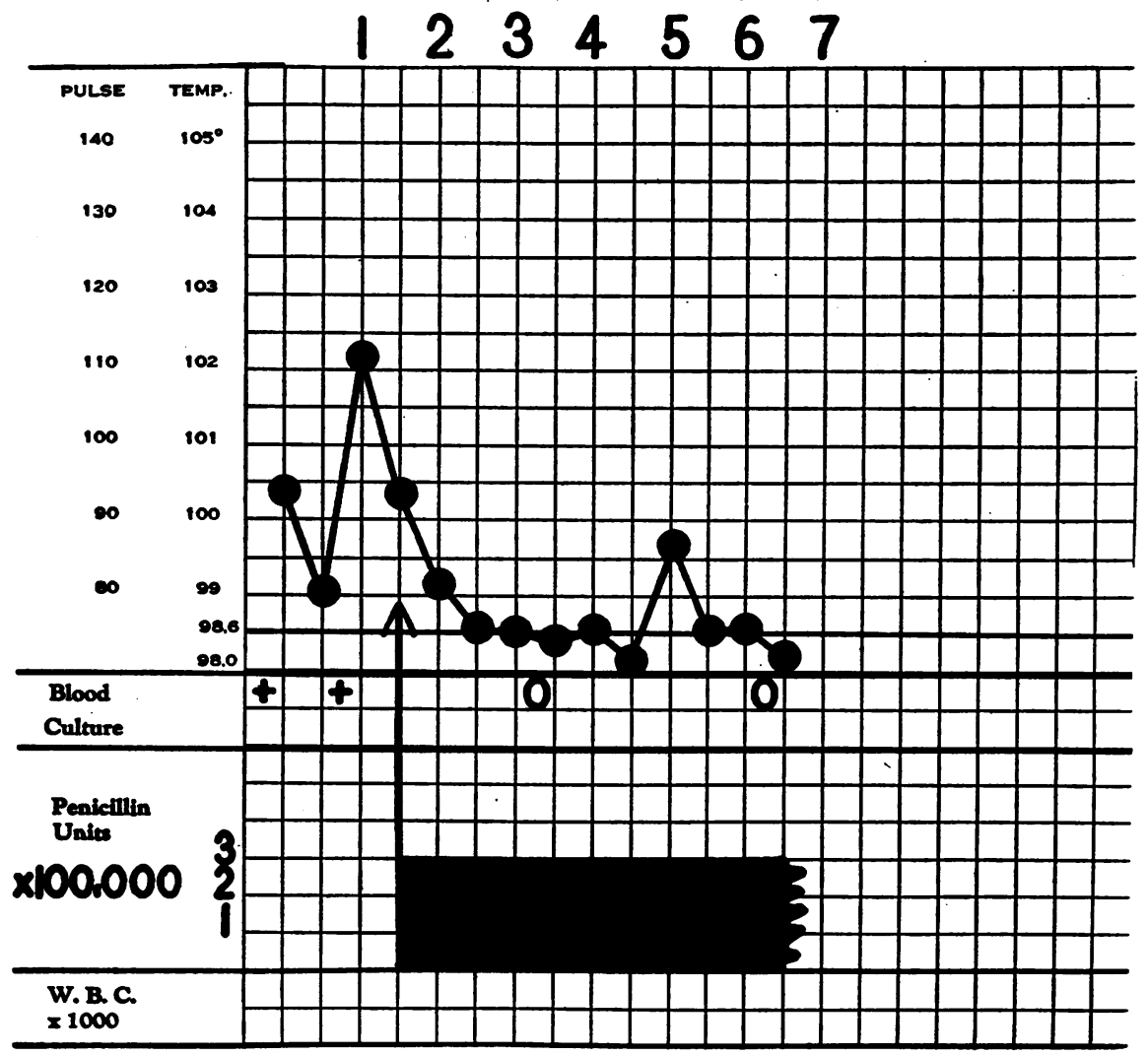

Fig. 8. Temperature Curve of Case 8 for the First Week of Treatment

Except for febrile reactions on the 9 th and $32 \mathrm{~d}$ days, probably from pyrogenic solutions, the temperature remained essentially normal.

petechiae. Blood culture yielded 70 colonies of $S$. viridans per $\mathrm{ml}$. This patient received intramuscular injections of calcium penicillin from the start, 200,000 units daily for the first month and 120,000 units daily for the second month-a total of $9,860,000$ units. There was a gradual fall in temperature but slight elevations persisted up to discharge (see Figure 9 and the tables). Blood cultures promptly became sterile and all symptoms cleared up. She left the hospital clinically well. Six weeks later she was in the hospital for a week for follow-up studies. The highest daily rectal temperatures were about $37.5^{\circ} \mathrm{C}$., blood culture was sterile, and she felt well although the heart signs were unchanged. Investigation of kidneys by excretory pyelography, because of persistent changes in urinary sediment, revealed an appearance suggestive of polycystic kidneys.

Case 10. A 29-year-old bookkeeper had no history of rheumatic fever but was said to have had an enlarged heart since childhood. He had been short of breath on effort for a long time. About a month before entry, he had what was called "flu," followed by bilateral flank pain for 12 days. Blood cultures were positive for $S$. viridans. Examination showed an acutely ill man with high fever, greatly enlarged heart, systolic and presystolic apical murmur, palpable spleen, and tenderness in right flank. There was no frank decompensation at this time. He was started on penicillin intravenously (see Figure 10 and the tables) but seemed unable to accommodate the required amount of fluid. There were several episodes which seemed to be associated with pulmonary and renal infarcts. It was thought that some of the spikes of high fever might be associated with transfusion reactions but even after these were stopped the temperature stayed high until the 21 st day of treatment when it fell rapidly to almost normal. The blood cultures, however, were negative on the second day of therapy and remained so throughout. He was given penicillin intensively for 60 days mostly by the intramuscular route (Figure 10). As his infection improved, frank signs of cardiac failure developed and he was sent to another hospital for continued rest.

Here, then, is an instance of probable extirpation of the infection but with sufficient damage to precipitate cardiac failure. It is also of note that this patient's strain was not inhibited in the test tube with concentrations of penicillin less than 0.1 units. per $\mathrm{ml}$. of media. 


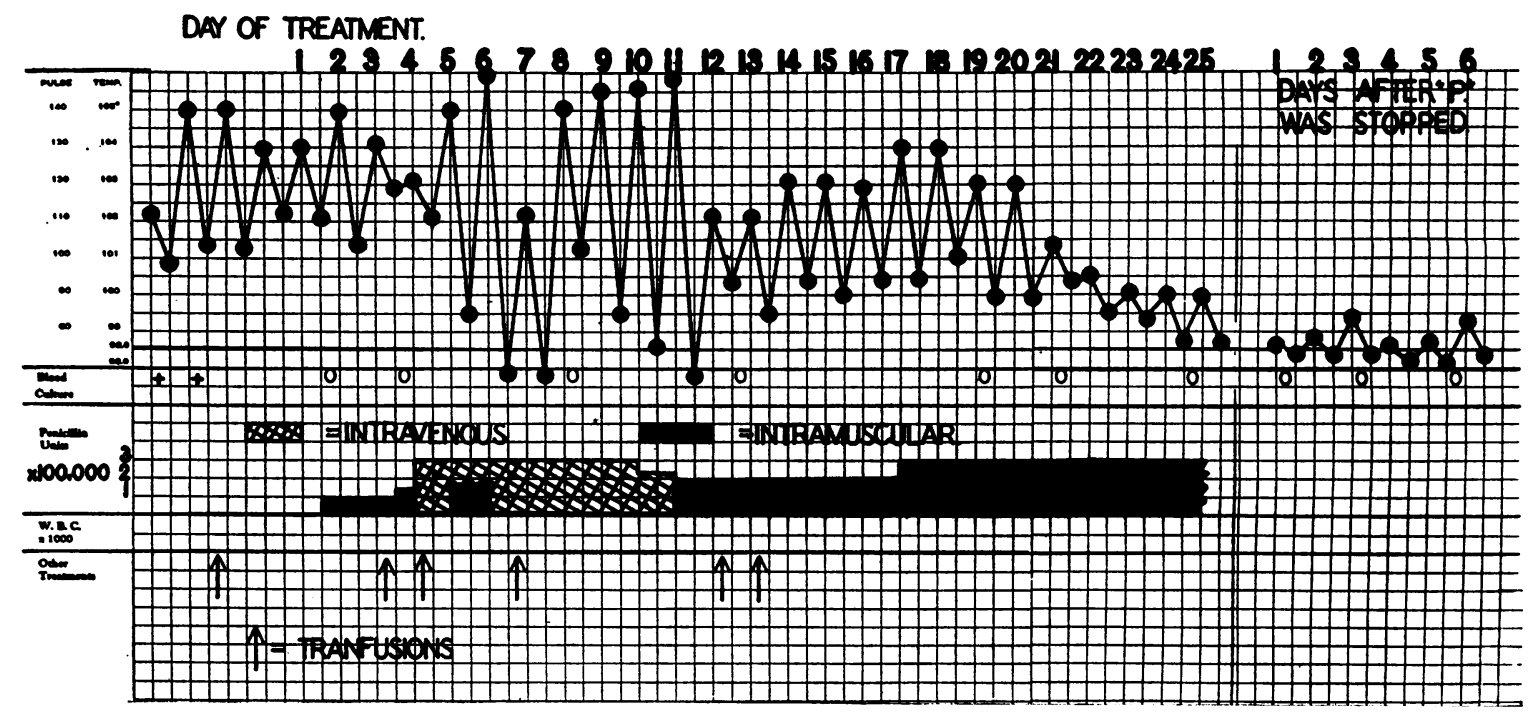

Fig. 9. Temperature Curve from Case 9

In spite of this relative resistance, blood cultures promptly became negative.

Finally, the importance of prolonged treatment is brought out, as one might well have considered him a failure at the end of 3 weeks when the fever was still high.
Case 11. A 23-year-old man had had "St. Vitus dance" at the age of 12 followed by "heart trouble." $\mathrm{He}$ had gotten along all right, however, until 3 months before entry when he developed increasing fatigue, cough, swollen ankles, and fever. A blood culture was positive for $S$. viridans and he was sent to Stanford Hospital

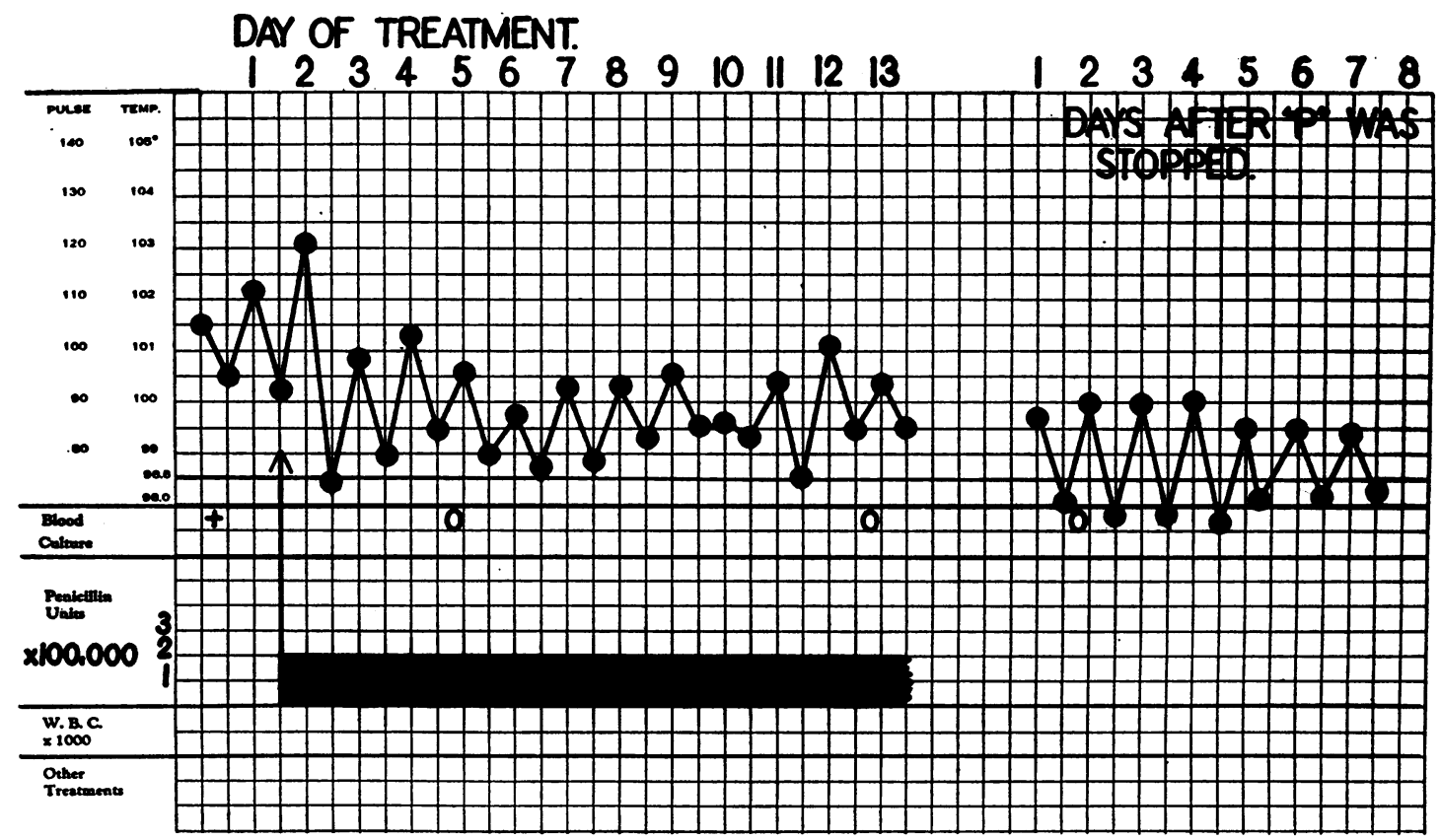

Fig. 10. Temperature Curve from Case 10 Showing First 25 Days of Therapy and First Week After Penicillin Was Stopped

It was only after 3 weeks of treatment that fever subsided. 


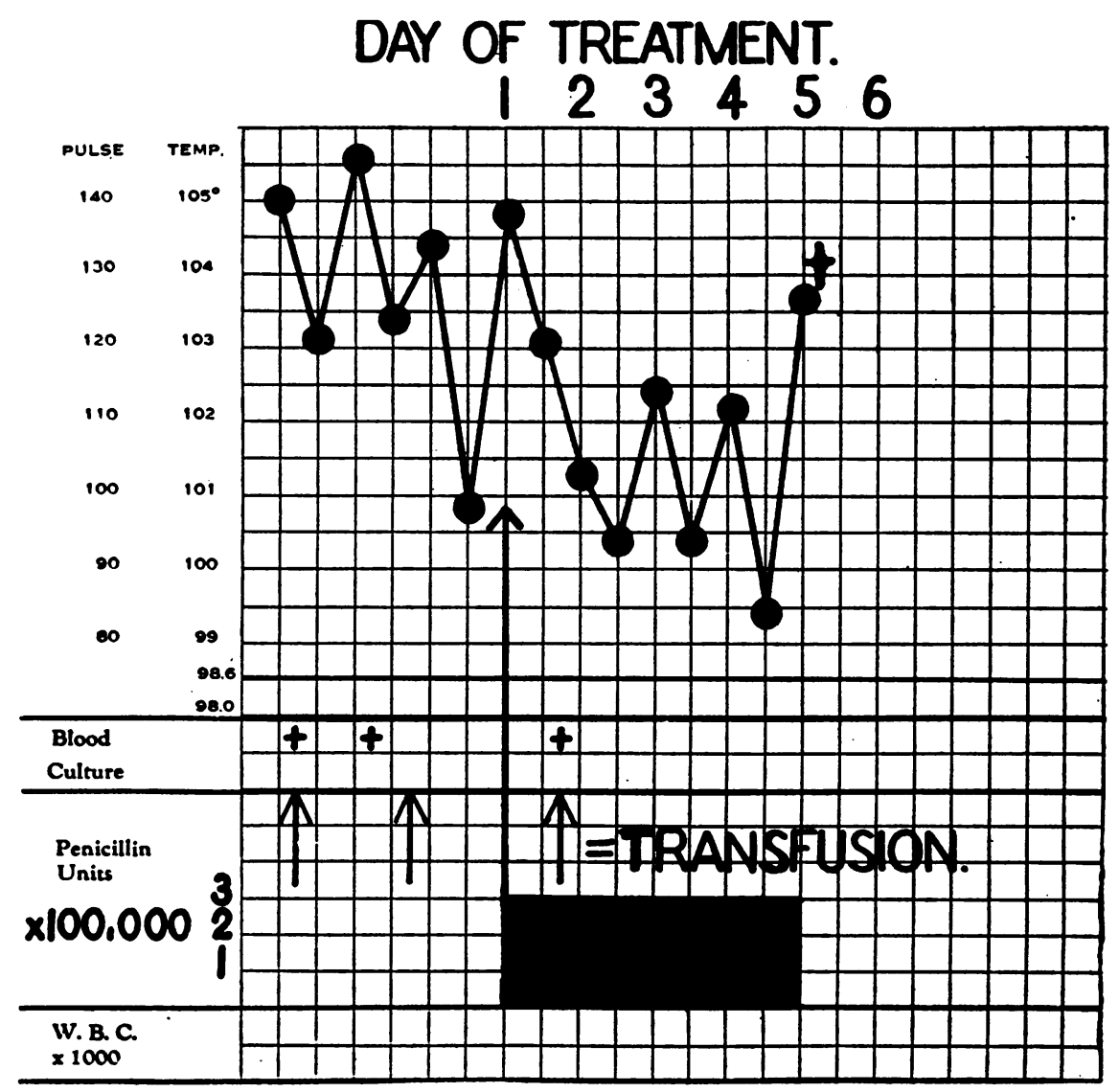

Fig. 11. Temperature Curve from Case 11

for penicillin therapy. On examination, he looked sallow and tired. There was clubbing of the fingers but no petechiae were seen. The spleen was palpable. He was somewhat dyspneic. The heart was markedly enlarged and there was a loud aortic diastolic murmur. The blood pressure was read at $175 /$ ?. There were some râles at the bases. There was high fever and marked anemia with packed cell volume of only 32 , red blood cells $2.9 \mathrm{M}$, and white blood cells 18,000 . The urine showed the sediment of a marked glomerulitis. Blood culture on entry yielded 50 colonies of non-hemolytic streptococci per ml. of blood. The strain was highly sensitive to penicillin and although he did not quite meet the specifications which we had laid down, it was decided to treat him. Penicillin was started by intramuscular injection every 3 hours at the rate of 300,000 units in the 24 hours. The temperature fell somewhat with prompt improvement in well-being. On the fourth day, out of a clear sky, there was sudden collapse with rapid feeble pulse, prostration, sweating, and death in a few hours (see Figure 11 and the tables).

Autopsy showed a huge oval vegetation loosely attached to the aortic valve but there was no coronary artery or pulmonary embolus and no rupture of a my- cotic aneurism. In short, no cause of death was found. It was thought that the mobile vegetation might have occluded the mouth of a coronary artery but this was purely speculative. At any rate, it seemed clear that penicillin had nothing to do with his death. The same lot was given to many other patients without reaction. There were no intravenous injections.

While the case is included in the series, it really can not be considered a "penicillin failure."

\section{Immediate effects}

RESULTS

The first and one of the most striking effects of penicillin therapy in many cases was an improvement in general well-being. Within a few days, in some cases within 24 hours, the patients insisted they felt better. One got the impression that "toxemia" had been lessened; appetite improved, and there was a desire for increased activity, reading, etc. To some extent, these changes went hand in hand with drop in temperature, but by no means altogether. 


\section{Effects of treatment on fever}

In 8 of the 11 cases, there was a prompt and striking drop of temperature to a practically normal level of not over $37.5^{\circ}$ to $38^{\circ} \mathrm{C}$. (rectal). One patient died on the 4th day of treatment (Case 11), and in Case 10, the temperature showed no definite decline for the first 3 weeks of treatment but then came down. This patient had a strain of streptococcus which was relatively resistant in the test tube. After the initial drop of fever, the temperature remained essentially normal in some cases. In others, a flat curve was disturbed from time to time by greater or lesser elevations, perhaps due to emboli, or perhaps to pyrogenic reactions or to phlebitis associated with intravenous therapy. In still other patients, after the initial drop, a low fever continued more or less throughout the hospital stay. This we were inclined to regard as part of the disease perhaps associated with absorption and with healing of lesions even after the patient was "bacteriafree." However, an examination of the curves obtained during the last week of hospital stay, after penicillin injections had been stopped, showed the highest temperature (rectal) in any case to be under $38^{\circ} \mathrm{C}$.

All in all the fever curves suggest that treatment should be continued over a long period in order to obtain the most secure results, even though an occasional patient may be "cured" with a short course of penicillin.

The findings described are illustrated in Figures 1 to 11 .

\section{The effect of penicillin on the blood culture}

When the patient is receiving large doses of penicillin, enough of the antibiotic may be carried over from the blood stream to inhibit organisms which otherwise could be grown in culture. For this reason,"penicillinase" (3) was added to the media with many of our blood cultures in order to prevent spurious "negative" results. As seen in Table II, the blood stream was sterilized with great promptness in practically all cases. Indeed, after the first few days, no positive culture was ever obtained in any patient, although in the whole series, 52 cultures were made during the period of penicillin therapy and 71 cultures were made during the follow-up period after peni- cillin was stopped. This differs somewhat from the experience of others (4) with patients treated for relatively short periods, to the effect that there is a marked tendency to relapse within a few days to a few weeks after the discontinuation of penicillin. We are inclined to ascribe the results obtained so far in this series to the time factorthe continuous treatment over a long period ( 6 to 8 weeks).

The detailed data are given in Table II. It is to be noted that there was no relation between the degree of bacteremia and the readiness with which the blood stream was sterilized, or indeed with the subsequent course. The paramount point seems to be the sensitiveness of the strain in question, although further statistics on this point are necessary.

Case 5 is of particular importance since a spike of fever on the fifth day was associated with a positive blood culture (see Figure 5). This suggests that viable organisms may lurk in the depths of the vegetations for some time.

\section{Petechial spots}

The relation of petechial spots to bacteremia has not, as far as we know, been exactly established. It seems of particular interest, therefore, to study the occurrence of petechiae before and after penicillin therapy. Among the 11 patients, there were 4 in whom none was seen at any time. Case 2, on entry, had the most profuse eruption we have ever observed in bacterial endocarditis. The skin, conjunctivae, and buccal mucosa were peppered with innumerable spots. Showers of fresh lesions continued for the first 4 days of penicillin therapy; thereafter, fewer spots appeared; and after the 2 weeks of therapy, no more were seen. The blood culture on the other hand was negative after one day of treatment and bacteria were never again grown from the blood stream.

The following table (Table III) summarizes the findings in all the cases. It is seen that petechiae continued to appear in many cases long after bacteria could no longer be obtained from the blood. Negative blood cultures do not, of course, prove the complete absence of bacteria from the blood stream, but petechiae ultimately were no longer found and this we were inclined to associate with "healing" of the lesions. 
TABLE II

Effect of penicillin therapy on the blood culture

\begin{tabular}{|c|c|c|c|c|c|c|}
\hline \multirow{3}{*}{$\begin{array}{l}\text { Case } \\
\text { no. }\end{array}$} & \multirow{3}{*}{ Blood cultures before "P" was started } & \multirow{3}{*}{ First culture after "P" was started } & \multicolumn{4}{|c|}{ Subsequent cultures (number) } \\
\hline & & & \multicolumn{2}{|c|}{$\begin{array}{l}\text { During "P" } \\
\text { therapy }\end{array}$} & \multicolumn{2}{|c|}{$\begin{array}{l}\text { After "P" therapy } \\
\text { was concluded }\end{array}$} \\
\hline & & & Neg. & Pos. & Neg. & Pos. \\
\hline 1 & $\begin{array}{l}S . \text { viridans }-70 \text { cols. per } \mathrm{ml} \text {. } \\
S \text {. viridans }-25 \text { cols. per } \mathrm{ml} \text {. }\end{array}$ & Neg. (4th day) & 4 & $\mathbf{0}$ & 10 & 0 \\
\hline 2 & S. viridans $-400+$ cols. per $\mathrm{ml}$. & Neg. (after 1st day) & 2 & 0 & 12 & 0 \\
\hline 3 & S. viridans-a few cols. per ml. & Neg. (4th day) & 4 & 0 & 9 & $\mathbf{0}$ \\
\hline 4 & Non-hemolytic strep. -25 cols. per ml. & Neg. (1 month) & 1 & 0 & 10 & 0 \\
\hline 5 & Non-hemolytic strep. -25 cols. per ml. & $\begin{array}{l}\text { Pos. (5 day) a few cols. per ml. } \\
\text { associated with chill and fever }\end{array}$ & 6 & $\mathbf{0}$ & 10 & 0 \\
\hline 6 & $\begin{array}{l}\text { Non-hemolytic strep. }-40 \text { cols. per } \mathrm{ml} \text {. } \\
\text { Non-hemolytic strep. }-25 \text { cols. per } \mathrm{ml} \text {. }\end{array}$ & $\begin{array}{l}\text { Pos. ( } 1 \text { day) less than } 1 \text { col. per } \mathrm{ml} \text {. } \\
\text { Neg. ( } 2 \text { day) }\end{array}$ & 10 & 0 & 4 & $\mathbf{0}$ \\
\hline 7 & S. viridans-26 cols. per $\mathrm{ml}$. & Neg. (2 hours) & 10 & 0 & 3 & 0 \\
\hline 8 & $\begin{array}{l}\text { S. viridans }-2 \text { cols. per } \mathrm{ml} \text {. } \\
\text { S. viridans }-8 \text { cols. per } \mathrm{ml} \text {. }\end{array}$ & Neg. (3 day) & 3 & 0 & 9 & $\mathbf{0}$ \\
\hline 9 & S. viridans -70 cols. per ml. & Neg. (5 day) & 7 & 0 & 2 & 0 \\
\hline 10 & $\begin{array}{l}\text { S. viridans }-8 \text { cols. per } \mathrm{ml} \text {. } \\
\text { S. viridans }-2 \text { cols. per } \mathrm{ml} \text {. }\end{array}$ & Neg. (2 day) & 6 & $\mathbf{0}$ & 2 & 0 \\
\hline 11 & $\begin{array}{l}\text { Non-hemolytic strep. }-50 \text { cols. per } \mathrm{ml} \text {. } \\
\text { Non-hemolytic strep. }-50 \text { cols. per } \mathrm{ml} \text {. }\end{array}$ & Pos. (1 day) 15 cols. & No & $\begin{array}{l}\text { tak } \\
\text { men }\end{array}$ & - died & th day \\
\hline
\end{tabular}

\section{Embolic phenomena}

Gross embolic phenomena were not always easy to identify since bouts of fever might be due to pyrogenic reactions from penicillin solutions or to phlebitis set up by intravenous injections. However, in 5 cases, there was no suggestion of emboli at any time. In Case 7, occasional elevations

TABLE III

Relation of petechiae to positive blood culture

Blood culture negative

(day of treatment)

3 (first culture)

4 (first culture)

2 (second culture)

102 (first culture)

$2 \quad 2$ (first culture)

511 (second culture)

First culture posi-

tive on 5 th day

14 (first culture)

\section{Petechiae}

Occasional up to 35 th day of treatment

Occasional up to $33 \mathrm{~d}$ day of treatment

Occasional up to 29th day of treatment

Occasional up to 28th day of treatment

Profuse for 4 days; some up to 14th day of treatment

Very few petechiae up to 7 th day of treatment was started
None seen after treatment of temperature which may have been associated with emboli persisted up to the 50th day of treatment. Case 6 had splinter hemorrhages and painful finger tips up to the 45th day. In Case 3, definite splenic and pulmonary infarcts occurred until the 33d day. Case 10 had frequent emboli to lungs, kidneys, and other situations up to the 28th day. In Case 5, spikes of fever-doubtless associated with emboli since there was a positive blood culture in one such episode-persisted through the 29th day, and in Case 2, there were probable embolic episodes for the first 3 weeks.

It seems clear, then, that emboli may continue long after blood cultures are negative. This one might expect because even if the lesions have been sterilized, particles of vegetation would probably continue to break away during the early stages of healing.

\section{Palpable spleen}

In 6 of the 11 patients, the spleen was not felt at any time. In Case 6, the edge was felt up to 
the 31 st day but not thereafter. In Case 10, the spleen, at first $3 \mathrm{~cm}$. below the costal margin, could not be felt after the 21st day, and in Case 3, the spleen which had been readily felt was no longer palpable after the third week of therapy. In Case 7, the spleen which was noted several finger-breadths below the costal margin on a number of occasions was never felt after the fifth day of therapy. In another patient, not included in the present series and still under treatment, the spleen which at first was a full hand's breadth below the costal margin receded almost completely within the first week of therapy. The exact anatomical explanation of decrease in size of spleen is not clear, but is probably associated with diminution of infiltration of certain cell types (5).

\section{Clubbing of fingers}

In the present series, perhaps because many of the cases were early, clubbing of the fingers was seen in only 4 , or 36 per cent. In Case 2 , clubbing already present on entry progressed acutely with symmetrical redness, swelling, and tenderness of the ends of all fingers and toes. Case 11 died on the fourth day of treatment so the course of his clubbing under penicillin could not be observed; in Case 6, the appearance present on entry seemed to become more marked as the patient improved, but in Case 3, slight clubbing definitely receded under treatment. The observations are too limited to justify further comment.

\section{Change in cardiac physical signs}

Since most instances of subacute bacterial endocarditis occur in connection with previously damaged valves, the question of how much these structures are further injured by the infectionespecially with reference to impairment of cardiac function-becomes of great importance. In 7 of the 11 cases, no change in the character of murmurs or other physical signs was noted during the entire period of observation. Case 3 developed a moderate tachycardia (rate approximately 100 per minute) which had not been present before treatment. No definite explanation such as hyperthyroidism could be proved. In Case 6 , there was a change in the quality of the first sound at the apex which became "less snapping" and the systolic murmur became much louder and almost "musical." Case 2 was of particular importance since there was an autopsy. Five months after entry and 3 months after penicillin treatment was concluded, it was noted that "The cardiac signs are now different from those on entry. The first sound (at apex) is less snapping and is followed by a loud systolic murmur well heard in the back (this loud murmur not present at first). There has doubtless been some anatomic alteration of the valve." At autopsy there was mitral stenosis but what had obviously been larger vegetations were now represented by very small flat hard and to some extent calcified patches. The net result however was marked destruction of the valve, which perhaps promoted the cardiac failure from which the patient died 3 months after treatment was completed.

These observations suggest that, unless treatment is started early in the disease, irreversible damage to valves may occur, even though penicillin may extirpate the infection.

\section{Changes in cardiac function}

The points discussed in the last paragraph open the question of possible changes in cardiac function in connection with bacterial endocarditis. According to some writers, the frequency of cardiac failure in this disease, as well as the presence of myocardial changes, has not been sufficiently emphasized $(6,7)$. Other pathologists have not been impressed by the importance of such lesions in bacterial endocarditis. It seemed of particular interest therefore to look for signs of cardiac failure, if any, in patients rendered bacteria-free by penicillin. Of the 11 patients, only 1 (Case 11) showed evidence of cardiac failure before treatment. There were dyspnea, edema, râles at the bases, engorgement of the liver, tachycardia, and gallop rhythm. This patient died on the fourth day of penicillin therapy, possibly from obstruction of a coronary artery by a mass of vegetation. In 6 cases, there was no suggestion of cardiac failure at any time during our period of observation. Case 3 developed a moderate tachycardia which persisted during the follow-up period, but he was very active and without symptoms. In Case 10, there was no frank failure on entry but gradual development of mild decompensation with dyspnea, basal râles, swollen liver, edema, and weakness which has necessitated continuous hos- 
pitalization although he is afebrile and bacteriafree. Case 2 (q. v.) gradually developed failure after penicillin treatment was completed. There was dyspnea, edema, râles, and increased venous pressure. These symptoms were intractable under standard cardiac therapy and she died in the hospital. Case 6, finally, at the end of the follow-up period felt very tired and became short of breath on slight effort.

In summary, then, in 3 of 11 patients, in spite of prompt clearing of the active bacterial infection, evidence of cardiac weakness supervened. These findings suggest that the insult from such infection may so damage valves or myocardium as to cause an irreversible impairment of cardiac function. This hazard must be taken into account in evaluating the ultimate outlook for patients with bacterial endocarditis "cured" by penicillin.

\section{Changes in electrocardiogram}

Electrocardiograms were taken from time to time in all the patients. In 8 cases, there were no significant changes. In Case 6 , minor $T$ wave and axis changes occurred, in Case 2 there were quite marked changes in $\mathrm{T}$ waves and in electrical axis, and in Case 10 there were changes in $P$ waves, $T$ waves, and axis. It is of interest that all these 3 patients developed more or less evidence of cardiac failure (see preceding paragraph).

\section{Blood count}

Only 2 of the patients were very anemic before penicillin therapy was started. The count on entry and the last count before discharge are shown in Table IV. It is seen that the blood was essentially normal in all cases at the end of treatment although transfusions were given to 6 patients. Leukocyte counts moderately elevated before therapy were all normal before discharge.

\section{Renal lesions}

Careful studies of the urinary sediment by the methods of Addis were done (C. D. A.) in order to study the effect of penicillin therapy on the renal lesions of bacterial endocarditis. It is not the purpose now to go in detail into the exact nature of these lesions but it is generally agreed that some sort of glomerulitis is the outstanding finding, and that the presence of abnormal num-
TABLE IV

Blood counts on entry and on discharge

\begin{tabular}{|c|c|c|c|c|c|c|c|}
\hline \multirow{2}{*}{$\begin{array}{c}\text { Case } \\
\text { no. }\end{array}$} & \multicolumn{3}{|c|}{ On entry } & \multicolumn{3}{|c|}{ Before discharge } & \multirow{2}{*}{$\begin{array}{l}\text { Trans- } \\
\text { fusion }\end{array}$} \\
\hline & $\underset{\text { (Sahli) }}{\text { Hgb }}$ & R.B.C. & W.B.c. & $\underset{\text { (Sahli) }}{\text { Hgb. }}$ & R.B.C. & W.B.C. & \\
\hline $\begin{array}{r}1 \\
2 \\
3 \\
4 \\
5 \\
6 \\
7 \\
8 \\
9 \\
10 \\
11\end{array}$ & $\begin{array}{c}\text { per cent } \\
68 \\
72 \\
73 \\
86 \\
83 \\
70 \\
72 \\
68 \\
72 \\
50 \\
56\end{array}$ & $\begin{array}{l}\text { million } \\
3.96 \\
4.10 \\
3.90 \\
5.50 \\
5.20 \\
4.00 \\
4.20 \\
4.25 \\
4.08 \\
2.70 \\
2.90\end{array}$ & $\begin{array}{r}14,600 \\
16,500 \\
10,900 \\
10,500 \\
11,900 \\
9,000 \\
14,000 \\
10,700 \\
11,300 \\
13,000 \\
17,800\end{array}$ & \begin{tabular}{|c|} 
per cent \\
80 \\
85 \\
95 \\
92 \\
81 \\
80 \\
88 \\
92 \\
75 \\
82 \\
Died o \\
da
\end{tabular} & $\begin{array}{c}\text { million } \\
4.40 \\
5.00 \\
5.10 \\
5.18 \\
5.00 \\
4.00 \\
4.50 \\
4.98 \\
4.10 \\
5.00 \\
\text { on } 4 \text { th } \\
y\end{array}$ & $\begin{array}{r}7,800 \\
7,400 \\
6,800 \\
7,800 \\
9,000 \\
9,000 \\
9,200 \\
10,000 \\
8,800 \\
7,800\end{array}$ & $\begin{array}{l}\text { Yes } \\
\text { Yes } \\
\text { Yes } \\
\text { No } \\
\text { No } \\
\text { Yes } \\
\text { No } \\
\text { Yes } \\
\text { No } \\
\text { Yes } \\
\text { Yes }\end{array}$ \\
\hline
\end{tabular}

bers of red blood cells in the urine is the most constant expression of the disorder.

The results are shown in Table V. Briefly, while the intensity of the process as judged by the urinary sediment was usually diminished, the lesions apparently did not heal altogether except perhaps in Case 7 who had very slight changes from the start. Case 2 at autopsy showed only a few scarred glomeruli and it is quite possible that a progressive lesion was arrested by elimination of the streptococcal infection. That this does not always result, however, we have pointed out elsewhere (8). At any rate, long observation with correlation of sediment and histological changes will be necessary in other cases before the final answer is obtained.

\section{Reactions and untoward effects}

Complaints of soreness in the buttocks were negligible in spite of the large number of injections which during the course of weeks amounted to several hundred. In a few cases, temperature which had remained slightly elevated became normal when the injections were stopped. This suggests that there was a mild reaction associated with the trauma of frequent hypodermics. In some patients, slight elevations of temperature, or occasionally a sharp spike may have been due to non-specific pyrogenic material. Two patients had transient mild urticarial eruptions. The majority of those who received prolonged intravenous infusions of penicillin developed phlebitis. of su- 
TABLE V

Effect of penicillin therapy on the renal lesion of bacterial endocarditis as shown by study of urinary sediment

\begin{tabular}{|c|c|c|c|c|}
\hline $\begin{array}{l}\text { Case } \\
\text { no. }\end{array}$ & $\begin{array}{l}\text { Degree of } \\
\text { lesion at } \\
\text { start of } \\
\text { treatment }\end{array}$ & $\begin{array}{l}\text { Degree of } \\
\text { lesion at } \\
\text { end of } \\
\text { treatment }\end{array}$ & $\begin{array}{l}\text { Degree of } \\
\text { lesion at } \\
\text { last } \\
\text { follow-up }\end{array}$ & Course \\
\hline $\begin{array}{l}1 \\
2\end{array}$ & $\begin{array}{c}++ \\
+\end{array}$ & $\begin{array}{l}++ \\
++\end{array}$ & + & $\begin{array}{l}\text { Improved } \\
\text { Died-Autopsy: } \\
\text { a few scarred } \\
\text { glomeruli }\end{array}$ \\
\hline $\begin{array}{r}3 \\
4 \\
5 \\
6 \\
7 \\
8 \\
9 \\
10 \\
11\end{array}$ & $\begin{array}{c}0 \\
++ \\
+ \\
++ \\
++ \\
+++ \\
+++ \\
++\end{array}$ & $\begin{array}{c}++ \\
0 \\
0 \\
++ \\
0 \\
+ \\
+ \\
+++\end{array}$ & $\begin{array}{c}+ \\
0 \\
0 \\
+ \\
0 \\
+ \\
+ \\
\text { No exam. }\end{array}$ & $\begin{array}{l}\text { Improved } \\
\text { Improved } \\
\text { Well } \\
\text { Improved } \\
\text { Improved } \\
\text { No change } \\
\text { Died-Autopsy }\end{array}$ \\
\hline
\end{tabular}

4 plus = Large numbers of R.B.C., white and epithelial cells, many casts, and increase of protein output.

1 plus = A slight increase in output of R.B.C. and W.B.C., possibly a few casts and a trace of protein.

$2+3$ plus $=$ Intermediate findings.

perficial arm veins which subsided with rest and compresses.

In summary, it may be said that intensive penicillin therapy over long periods of time was unassociated with any toxic effects attributable to the material itself.

\section{Late results}

The present report is concerned mainly with the immediate course of events under penicillin therapy even though the follow-up periods extended up to 6 months. Case 11 died on the fourth day of treatment-too soon to draw any conclusions. All the other patients, as evidenced by clinical findings and blood culture, were rendered bacteria-free ${ }^{2}$ and we were inclined to regard them as "cured" (see Table VI). In Case 2 , however, the findings at autopsy of cocci in the depths of the "healed" valve lesion makes it necessary to modify any positive statement. Should bacteremia and clinical symptoms recur, one might be dealing with either reinfection or relapse, and a comparison of strains from the original and subsequent attacks would be necessary to settle the matter. Full understanding of the whole situation is obviously contingent on long periods of

2 Throughout this paper bacteria-free means that repeated blood cultures, using broth flasks and poured blood agar plates, yielded no growth.
TABLE VI

Summary of results of treatment

Total cases

Rendered bacteria-free

Rendered bacteria-free and clinically

"cured" except for old signs of heart lesion

Clinically cured of active infection

after follow-up period of from 2 to 6 months

Rendered bacteria-free but died later in cardiac failure

Rendered bacteria-free but signs of cardiac failure later

Death during treatment (4th day) unexplained

Relapses or reinfections

$\begin{array}{cc}\text { No. } & \text { Per cent } \\ 11 & 100 \\ 10^{*} & 91 \\ & \\ 8 & 73 \\ & \\ 8 & 73 \\ 1 & 9 \\ 1 & 9 \\ 1 & 9 \\ 0 & 0\end{array}$

* The one patient not rendered bacteria-free died on the fourth day of treatment. No culture had been made since the second day.

"Bacteria-free" throughout this paper refers to a status in which the blood culture repeatedly yielded no growth.

observation and more autopsies in "apparently healed" cases.

As to functional results, 7 of the 11 patients are back at work and apparently as well as before bacterial endocarditis developed. One patient after a short follow-up period still feels tired and is short of breath on effort although there are no signs of infection, and another, although bacteria-free, now has frank cardiac failure. One patient is dead of cardiac failure (Case 2) and one patient died early in the course of treatment.

There seemed no doubt about the relation of therapeutic effect to strain sensitivity and unless the organism is readily inhibited in the test tube it seems hardly worthwhile starting treatment. A young man had a bacterial infection in connection with a patent ductus arteriosus. A nonhemolytic streptococcus isolated from the blood grew freely in high concentrations of penicillin. Intensive therapy consisting of as much as 500,000 units per day by continuous intravenous infusion failed to lower fever or to reduce the bacteremia. Another patient, a young woman, with all the typical clinical features of bacterial endocarditis, was treated in spite of the fact that numerous blood cultures yielded no growth. There was no benefit and later influenza bacilli were recovered from the blood stream on 3 occasions.

\section{DISCUSSION}

With the exception of 1 who died of unexplained causes early in the course of treatment, 
10 consecutive patients with bacterial endocarditis with strains of streptococcus sensitive to penicillin were rendered "bacteria-free" and clinically cured of the infection although 1 died later of cardiac failure. Seven, or well over half, are back at work and so far appear to be in as good health as before the infection.

The question comes up as to the explanation of these results in view of the high percentage of failures reported in the early days of penicillin treatment of bacterial endocarditis. We believe that the time factor is paramount and within limits perhaps even more important than the daily dose. Everything indicates that continuous treatment over a long period ( 2 months or more if necessary) is much more likely to extirpate the infection completely than brief runs of penicillin, even if the daily dose is large. Granting this premise, one wonders whether the technique of administration cannot be simplified. We are now trying an entirely new program consisting from the start of intramuscular injections of 50,000 units of penicillin given only 4 times in the 24 hours (at 6-hour intervals). Three patients now under treatment by this method have responded with prompt fall in temperature and clearing of the blood stream. But long time studies are obviously necessary to settle these questions and, as said above, the present paper deals mainly with the immediate effects of penicillin.

\section{CONCLUSIONS}

Intensive penicillin therapy over long periods (approximately 6 to 8 weeks) led to the following results in 11 patients with bacterial endocarditis caused by strains of streptococcus sensitive in the test tube.

1. All patients were promptly made "bacteriafree" (blood cultures) except one who died early in the course of treatment.
2. Eight, or $\mathbf{7 3}$ per cent, were clinically cured of the infection after follow-up periods up to 6 months.

3. One patient, apparently cured of the infection, died of cardiac failure. Cocci were seen in the depths of a scarred mitral valve. The significance of this observation is not clear.

4. There were no clinical relapses or reinfections.

5. Petechiae and emboli continued for some time after the blood cultures were negative.

6. Renal lesions as evidenced by studies of urinary sediment were not as a rule completely eliminated by the treatment.

\section{BIBLIOGRAPHY}

1. Keefer, C. S., Blake, F. G., Marshall, E. K., Jr., Lockwood, J. S., and Wood, W. B., Jr., Penicillin in the treatment of infections. J. A. M. A., 1943, 122, 1217.

2. Loewe, L., Rosenblatt, P., Greene, H. J., and Russell, M., Combined penicillin and heparin therapy of subacute bacterial endocarditis. J. A. M. A., 1944, 124, 144.

3. Kirby, W. M. M., Extraction of a highly potent penicillin inactivator from penicillin resistant staphylococci. Science, 1944, 99, 452.

4. Cf. Anderson, D. G., and Keefer, C. S., Treatment of Infections with Penicillin. Supplement to Sixth Edition of Cecil's Text-Book of Medicine, W. B. Saunders Co., Philadelphia, 1944.

5. Cf. Rich, A. R., Acute splenic tumor produced by non-bacterial antigens. Proc. Soc. Exper. Biol. and Med., 1935, 32, 1349.

6. Buchbinder, W. C., and Saphir, O., Heart failure in subacute bacterial endocarditis. Arch. Int. Med., 1939, 64, 336.

7. Saphir, O., Myocardial lesions in subacute bacterial endocarditis. Am. J. Path., 1935, 11, 143.

8. Bloomfield, A. L., Kirby, W. M. M., and Armstrong, C. D., A study of penicillin failures. J. A. M. A., 1944, 126, 685. 